\title{
Historia del léxico español y la red global: algunos ejemplos
}

\section{History of the spanish lexicon and World Wide Web: some exemples}

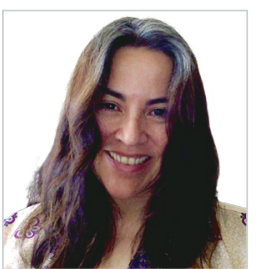

Soledad Chavez Fajardo. Profesora en el Departamento de Lingüística de la Universidad de Chile. Docente en el área de Lingüística histórica (Lingüística Románica, Historia de la Lengua española medieval y moderna, Historia del español de América y de Chile, Judeoespañol) y de Lexicografía española. Su investigación se centra en la historiografía lingüística y en la lexicología histórica.

Universidad de Chile, Santiago de Chile, Chile

schavez@uchile.cl

ORCID: 0000-0001-8173-8979
Recibido: 21/07/2020 - Aceptado: 24/10/2020

\section{Resumen:}

Queremos mostrar en este ensayo la relevancia de los medios digitales internacionales como corpus de investigación para hacer historia del léxico español. Queremos presentar algunas herramientas como corpus y bancos de palabras, especialmente elaborados para la tradición hispánica. Por ejemplo, queremos trabajar con proyectos de investigación en romanística o hispanística que están en la red de universidades anglosajonas, francesas o germánicas. O, además, bibliotecas en línea. Justamente, en este ensayo queremos presentar algunos casos en donde la investigación en lexicología histórica se complementó con los datos que aportó el ecosistema digital total. Para esta investigación nos centraremos en dos espacios de la lexicología hispánica, solamente: el de la etimología romance y el de la historia del léxico español americano.

\section{Palabras clave:}

Lexicología histórica; etimología; hispanística; romanística; diccionarios.

\section{Introducción}

Una investigación acerca del léxico, sobre todo en lo concerniente a su historia y a su etimología, requerirá siempre la búsqueda de datos y cotejo de información, sea en papel o en la red. Por lo tanto, los diccionarios, monografías y estudios del tema, así como la bibliografía pertinente o relacionada, además de la información que se encuentra en internet, serán

Cómo citar este artículo:

Chavez Fajardo, S. (2020). Historia del léxico español y la red global: algunos ejemplos. Doxa Comunicación, 31, pp. 403-419. https://doi.org/10.31921/doxacom.n31a20 research projects in Romance or Hispanic linguistics that are in the Anglo-Saxon, French or German university networks or accessible in online libraries. Particularly, in this essay, we present some cases where research in historical lexicology was complemented with data provided by the whole digital ecosystem. For this research, we will only focus on two áreas of Hispanic lexicology: that of Romance etymology and that of the history of the Spanish-American lexicon.

Keywords:

Historical lexicology; etimology; Spanish language studies; Romance language studies; dictionaries.
Hispanic tradition. For example, we would like to examine some 
fuentes fundamentales para hacer lexicología histórica. Sin embargo, muchas veces estas obras o todo tipo de información que aporte la hispanística, digamos clásica, será insuficiente. Lo mismo sucede con los bancos de palabras y corpus oficiales, como los que nos provee la Real Academia Española (como CORDE, CREA, CORPES XXI o la información en línea para el Nuevo Diccionario Histórico, para dar un ejemplo) o la Biblioteca Nacional de España (su Hemeroteca digital, por ejemplo). En esos momentos es cuando lo suyo es abrirse a otros espacios, los que pueden ayudar a complementar o comprobar lo que se está investigando. Lo que queremos dar cuenta en este ensayo es, justamente, la relevancia de los medios digitales internacionales como corpus de investigación para hacer historia del léxico español. En efecto, el ecosistema digital global constituye un espacio lingüístico fundamental y nos provee de datos algunas veces no tratados en la literatura oficial (académica, sobre todo). Asimismo, al no ser preponderante el filtro de la corrección normativa hispánica, muchas veces la información en red global aporta información relevantísima la que, dentro de los espacios, "codificados" podría no aparecer. En otros casos, lo que tenemos es la existencia de corpus y bancos de palabras especialmente elaborados para la tradición hispánica. Muchas veces son proyectos de universidades anglosajonas, francesas o germánicas y si no estamos al día en lo que se está investigando en relación con la romanística o la hispanística, podemos quedar fuera de todas estas herramientas que están en la red de libre acceso. Otras veces, como veremos en un caso, más que proyectos universitarios, de filólogos y lingüistas, lo que tenemos son bibliotecas en línea de proyectos que de buenas a primeras nos pueden, incluso, sorprender. En este ensayo queremos presentar algunos casos en donde la investigación en lexicología histórica se complementó con los datos que aportó, justamente, el ecosistema digital total. En este estudio, en síntesis, queremos dar cuenta de la relevancia del uso de internet como corpus lingüístico, más no el que nos provee la red en general, sino el que proveen las universidades del mundo, para el estudio del léxico español. Para ello nos centraremos en dos espacios de la lexicología hispánica, solamente: el de la etimología romance y el de la historia del léxico español americano.

\section{Metodología}

Por ser un trabajo de lexicología histórica, la metodología usada será la filológica, que implica la revisión y el cotejo de la voz estudiada en diversas fuentes bibliográficas, sean estas en papel o en la red. Partiremos con la problematización de una voz en cuestión, sobre todo acerca de su etimología, su vigencia o su extensión. Puede ser la puesta en duda de la etimología o procedencia que se ha venido trabajando de ella. También puede ser la alerta de la cuestión de una voz determinada: un filólogo o etimólogo informa acerca de un aspecto de la estructura de la voz en cuanto signo, aspecto que debe ser revisitado y estudiado. También puede ser la revisión (que debe ser constante) del étimo hipotético de una voz, bajo los avances de la etimología y la lexicología. Asimismo, puede ser la revisión crítica de las marcas diatópicas de una voz en un repertorio oficial (como lo es el diccionario académico) y relativizar o corroborar dicha información. En estos casos, la labor del lexicólogo histórico suele implicar, más que nada, un peritaje y cotejo de diccionarios, en primer lugar. Suelen ser diccionarios de lengua española y, las más veces y, dependiendo corte sincrónico de la voz en cuestión, suele trabajarse con diccionarios contemporáneos o tipológicamente afines a dicha voz (por ejemplo: diccionarios españoles decimonónicos, diccionarios etimológicos, diccionarios hispanoamericanos, diccionarios de chilenismos, diccionarios 
del Cono sur, entre otros). A su vez, se hace uso de los bancos de palabras oficiales españoles, los que suelen ser los que provee la RAE, o bancos como los que aporta la Hemeroteca digital. En casos en donde no haya algún tipo de información concluyente o definitoria, o haya alguna laguna que sea necesario comprobar, se hará uso de una serie de fuentes que nos provee la romanística o la hispanística internacional, entre otros espacios. Es decir, páginas que universidades internacionales, así como proyectos y centros de investigación financien para que los resultados estén a la mano del investigador o curioso. Por el modus operandi de la lexicología histórica, muchas veces la bibliografía revisada y citada no es actual, pero esto no implica que la investigación en sí esté desactualizada, para nada. Al contrario, la lexicología histórica requiere, las más veces, del examen exhaustivo de la bibliografía general respecto al uso y competencia de dicha voz, por lo que es de absoluta necesidad acudir a este tipo de referencias.

\subsection{Etimología: un caso de interferencia}

Un caso interesante dentro del quehacer etimológico es cuando, dentro de ese conflictivo cajón de sastre que es la etimología popular, se da con la clave de esta, que podría ser la similitud en la forma o fondo (o forma y fondo) de las voces en jaque. De esta similitud se produce lo que se conoce en semántica histórica como interferencia asociativa fonética (cfr. Kany 1962: 203-204), en donde se genera un intercambio de sonidos y sentidos entre dos voces. Por lo general, los etimólogos achacan falta de atención de los hablantes o, muchas veces, el desconocimiento del significado de la palabra, sobre todo de palabras extranjeras, dialectales, arcaicas o que puedan parecer extrañas al hablante.

2.1.1 Es lo que encontramos, de hecho, en baza, que se entiende como la Conjunto de cartas que en ciertos juegos de naipes recoge quien gana la mano (DLE); o ganar un jugador una mano y llevarse todas las cartas de los jugadores (DUE); o el hecho de tener la carta con más valor en la jugada (DEA) o todo el conjunto de naipes que se utilizan en cada jugada (CLAVE). Esto, a su vez, en la transición semántica de la voz derivó en toda una operación bien calculada (DEA) o una cosa que permita una ventaja o beneficio (DLE, DUE) o beneficio o pérdida (DEA).

2.1.2 En el Diccionario de Chilenismos y de otras voces y locuciones viciosas, que el sacerdote diocesano Manuel Antonio Román publicó entre 1901 y 1918 encontramos la siguiente pregunta respecto a la locución adverbial sentada esta baza o sentada la baza: " ¿cómo es que el Dicc. le cuelga a esta voz la loc. Sentada esta baza, o la baza, que interpreta "sentado este principio, o el principio; esto supuesto”? ¿No está aquí baza bramando de verse escrita con z, pues solo con s es como significa "principio y fundamento de cualquier cosa"?" (1901-1908: s.v. base o baza). La actitud crítica de Román ante la RAE derivó, al desglosarlo, en un interesante caso de peritaje etimológico.

2.1.3 Justamente, al indagar en la historia de la diccionarización de baza, vemos que, más que una aparente errata académica encierra un interesante caso de posible cruce homonímico. En efecto, Covarrubias (2006 [1611]) en el artículo basa agregó, como segunda acepción:

Basas, en el juego, son las cartas ganadas, las cuales van haciendo fundamento sobre la primera, de do tomaron el nombre. Cuando uno se lo habla todo, sin que otro alguno de los circunstantes pueda decir su razón, comúnmente se dice del tal, que no dejó hacer baça a los demás aludiendo al juego de las baças. (s.v. basa). 
Véase que la indistinción del grafema se da en el artículo mismo: este se inicia con basa y termina en baça, trueque que sorprende por lo tardío que es. En efecto, Alonso (1947) afirmaba que, en el siglo XVI, y aun antes, se encuentran algunas vacilaciones del tipo $s$ - $z$, incluso lo ejemplifica con los casos encontrados por Menéndez Pidal en La leyenda de los infantes de Lara, en pluma de un escribano toledano, así como con algunos ejemplos tomados de Cuervo en la misma rima en autores castellanos como el madrileño Juan Álvarez Gato en el XV. Por otro lado, Valdés, en sus Diálogos, también daba cuenta de estos trueques (1969 [1535]: § 89), sobre todo en algunos hablantes de Castilla. Alonso postula que este tipo de confusiones, en un estado donde el paradigma sigue teniendo pares de fonemas sonoros, implica trueques entre ellos, es decir, entre las sibilantes apicoalveolares, palatales y dentales, siempre en los casos, eso sí, de palabras aisladas (cfr. 1947: 8). Justamente, esta es la pista que no podemos dejar de lado en este caso: la posibilidad de la sonoridad en la sibilante de la voz.

2.1.4 Sigamos con el cotejo en los diccionarios de la época de Covarrubias: Rosal (1992 [1611]) lematizó basa y definió: "Basa en el naype, y fuera de él, es asiento o peana y grada en edificio, tomado del gr. basis; que tal forma representan las basas en el juego". Por lo tanto, encontramos tanto en Covarrubias como en Rosal, la alternancia gráfica basa /baza, en donde baza, voz que hace referencia a las cartas, puede ser escrita como basa. Los autores tratan ambas voces como derivadas de un mismo signo, basa, y con transición semántica: la primera carta es la basa (base) del resto en el juego, de ahí deriva, en transición semántica, el nombre del conjunto de cartas.

2.1.5 La tradición lexicográfica plurilingüe también nos da pistas interesantísimas. La mayoría de estos diccionarios lematizan la voz relacionada con las cartas en el mismo artículo lexicográfico de la 'base o fundamento', es decir, en basa, al igual que Covarrubias y Rosal, por lo que siguen tratando, más que con una homonimia, con una polisemia. Fuera de esto, encontramos que la voz posee variantes: Palet (1604), en su diccionario bilingüe francés-español, fuera de basa, también lematiza baça con el mismo significado. Oudin (1607), en su diccionario bilingüe francés-español, al igual que Palet, fuera de basa, también tiene baça con el mismo significado y remite, además, a un vaza. Vittori (1609), en su diccionario trilingüe francés, español e italiano, fuera de basa, remite a vaza, como Oudin. Minsheu (1617), en su diccionario trilingüe inglés, español y latino tiene basa. Franciosini (1620), en su diccionario español-italiano, fuera de basa, lematiza en otro artículo las dos variantes: baça y vaça. Mez de Braidenbach (1670), en su diccionario español-alemán lematiza las dos variantes juntas: basa y baça y Stevens (1706), en su diccionario español-inglés tiene basa.

2.1.6. Este panorama plurilingüe nos llevó a pensar en una posible indistinción, sobre todo avalado por ese basas-baças en Covarrubias y basa en Rosal, algo que se continua con la tradición lexicográfica plurilingüe, para empezar, poco a poco a decantarse el uso por la sibilante interdental baza, tal como vemos en los autores más tardíos de diccionarios bilingües, como Sobrino (1705), quien en su diccionario español-francés solo lematiza la voz en baça.

2.1.7. Ya en la tradición lexicográfica monolingüe, en la segunda edición de Autoridades (1770) se incorporó solamente baza con la significación de "en el juego de naipes es el número de cartas que recoge el que gana la mano". Sin embargo, es relevante que se sigan presentando casos de variantes, como en el Suplemento de Domínguez (1869), donde una de las acepciones de baza remite a basa. Nos detenemos en esto porque la crítica de Román se centra, justamente, en uno de los casos en donde la voz entra en fraseología, específicamente en la locución sentada esta/la baza, con el valor de "sentado 
este principio", locución que aparece por primera vez en la edición usual de 1783. Román achaca un posible error al diccionario académico y pensamos que, más que un error, lo que tenemos es una interferencia asociativa fonética.

2.1.8. En primer lugar, tenemos la voz baza, la cual hasta el día de hoy se le achaca una etimología discutida. Se pensó que podría venir del árabe, por lo que una larga tradición lexicográfica así lo advirtió: Autoridades (1990 [1726]), afirma que viene del árabe "vencer, sojuzgar, dominar", que pasa a "llevarse una cosa" en la edición de 1899 y a "ganancia conquistada en la disputa” en la edición de 1956. La tradición lexicográfica etimológica del siglo xix insiste en el arabismo: Echegaray (1887) y Barcia (1880), afirman que viene del árabe "vencer, porque el que hace la baza vence". Ya en la tradición lexicográfica etimológica del siglo xx, relativiza el DCECH (1980) la tesis arabista, puesto que la voz no aparece en los grandes repertorios lexicográficos árabes.

2.1.9. Sin embargo, dentro de la tradición lexicográfica etimológica del xix destacamos otra línea, con una hipótesis indoeuropea, en especial germánica. Tal es el caso de Calandrelli (1881), quien cita la tesis de Diez, en donde se propone que la voz viene del medio alto alemán bazze: "ganancia, beneficio, provecho", derivado del adjetivo baz: "bueno, provechoso, útil”, derivado, a su vez, del antiguo alto alemán baz o paz: "útil, provecho, bueno, excelente", con una base indo-europea bhad-. De allí derivan tanto baza como báciga ('antiguo juego de naipes'), propone Calandrelli, correspondiente al italiano bázzica y al catalán basa. Meyer Lübke (1935 [1911-1920]), posteriormente, objeta la tesis de Diez, sobre todo por las sibilantes en concurso en la voz, que no se condicen con la realidad románica de la voz.

2.1.10. Corominas y Pascual (en el DCECH 1980) propusieron que la voz podría haberse tomado del italiano bazza 'ganga, ganancia', de origen incierto y que ya estaba en italiano desde fines del siglo xv sin mayor información. Para poder justificar mejor esta propuesta y, por lo tanto, poder desentrañar la relación entre baza y basa en la locución que Román critica, nos hemos quedado sin mayor fuente o repertorio dónde indagar. He aquí, entonces, que los repertorios en papel quedan cortos y requerimos hacer una búsqueda en línea de lo que nos pueda aportar la romanística in extenso.

2.1.11. En efecto, hemos detectado en bancos de palabras actuales, como en el Tesoro della lingua italiana delle Origeni (TLIO), proyecto dirigido por Pietro Beltrami, que la voz ya estaba datada a principios del siglo xiv en el italiano (cfr. TLIO: Anonimo Genovese, 1311). El TLIO, a su vez, propone que la etimología viene del provenzal bauzejar 'frodare' ('defraudar'). Aquí nuevamente nos ayudó la lexicografía románica en línea, puesto que el Dictionnaire de L’Occitan Médiéval (DOM) nos confirma que bauzejar es, justamente, 'frauder' y que vendría de una raíz germánica *bauson, *bausjian (por lo que Diez y Calandrelli no estaban tan perdidos), algo que cotejamos en el Französisches Etymologisches Wörterbuch (FEW), también en línea, pero con este sentido, el de 'defraudar'.

2.1.12. Volviendo al espacio ibérico, la voz en cuestión, señala Corominas, pasó del italiano al catalán basa y al portugués vasa, ambas pronunciadas con la sibilante sonora, como la italiana. Este dato será fundamental para la posible confirmación de esta hipótesis, puesto que de ser sonora la sibilante y al ser un préstamo, podría haberse dado ese trueque tardío que hemos detectado en la primera tradición lexicográfica de la voz en español.

2.1.13. Como sea, el hecho de que se presente, a su vez, el homónimo basa, base como "fundamento o apoyo" y que la disposición formal del juego de cartas asimilaría a una base (algo que ya había comentado Covarrubias) generará el cruce con la baza. Esto, más el hecho de que la voz, en claro préstamo, tuviera una sibilante sonora ayudó a que vacilara su 
articulación y, por extensión, su grafía. De esta forma, esta suerte de “error" que ve Román no es más que el producto de este contexto léxico.

2.1.14. La última parte del artículo lexicográfico de Román da para reflexiones que se escapan de este ensayo. Justamente, son aspectos más ligados a la sociolingüística crítica o a la glotopolítica:

Sin duda los SS. Académicos oyeron la loc. de boca de algún andaluz, y como la oyeron así la escribieron, y así salió ella, cual digan dueñas. Más acertados andamos los chilenos, que hemos inventado y usamos familiarmente la fr. fig. hacer baza en el sentido de ganar o prosperar en cualquier asunto o negocio. Ú. m. con negación. (1901-1908)

Justamente, no podemos culpar al sacerdote chileno por el prurito ante el español andaluz: no manejaba él los datos etimológicos que pueden hacer desentrañar la maraña en lo que sucede con este étimo.

\section{Etimología hipotética y su enmienda}

Un trabajo necesario y constante dentro del quehacer etimológico es la enmienda de étimos, gracias a los avances de la disciplina o el descubrimiento de nuevos textos (sobre todo en los casos de los étimos hipotéticos) o de nuevas propuestas de estudio. En efecto, suele ser esta una disciplina que constantemente se está rehaciendo, en pos de la perfectibilidad. En el caso de un diccionario no etimológico como el académico, también se va modificando la información que dentro de los lemas se va integrando. En este punto debemos ser cuidadosos y justos: el DLE no es un diccionario histórico ni etimológico, pero al ser una obra mixta, incluye, dentro de su información, muchas veces la etimología o procedencia de la voz. Muchas veces esta información puede ser, con justa razón, puesta en duda o puede estar desactualizada; o bien, puede estar a la zaga de lo que haya propuesto Corominas, el único diccionario etimológico completo en lengua española vigente a la fecha.

3.1. Tomemos el caso de montaña, voz que se derivó, en la edición usual de 1947, de monte. Esa era la información que había dentro del comentario que corresponde a la etimología o a la derivación. Sin embargo, desde la edición usual de 1956 hasta la actualidad, la Academia, así como Calandrelli (1916) y Corominas (1981) propusieron un hipotético * montanea, neutro plural de un *montaneum, presente en Meyer-Lübke, (1935 [1911-1920]). Bien se sabe que, dentro del quehacer de la lexicología histórica, anteponer el asterisco responde a que la voz es una voz reconstruida, de la cual no se ha encontrado un texto que compruebe su existencia. Por lo que bien podríamos quedar hasta este estadio, el de reconocer y fundamentar un étimo hipotético reconstruido sin más.

3.2. Sin embargo, gracias al quehacer etimológico que se está haciendo fuera del dominio hispánico, tenemos posibles nuevas hipótesis. En efecto, y con esto queremos aportar algunos datos que puedan servir para informar a la comunidad no etimológica de las herramientas que hay en la red, mas no en lengua española. Justamente, en 1995, en el contexto del XXI Congreso de Lingüística Románica, una mesa redonda trató críticamente el tema de seguir la línea del monumental Französisches Etymologisches Wörterbuch (FEW), el trabajo etimológico, creemos, más completo que se ha redactado en lengua románica, obra que Walther von Wartburg redactó entre 1910 y 1940. De las reflexiones, proyecciones y desafíos de esa mesa redonda surgió, el año 2008, el proyecto Dictionnaire Étymologique Roman (DÉRom), cuya finalidad fue, justa- 
mente, gracias a los nuevos avances en la lingüística y digitalización de un número importante de tradiciones textuales, así como con la aparición de bancos de palabras, seguir trabajando con etimologías, pero ya para el mundo románico todo, teniendo siempre como referente metodológico el FEW. Los resultados se van renovando cada cierto tiempo y están abiertos en línea, por lo que uno puede ir consultando, con suerte o no, las novedades etimológicas.

3.3. En este contexto y como una forma de corroborar, por ejemplo, si se ha superado este hipotético *montanea es que decidimos revisar el DÉRom en donde se propone un protorrománico */montanial: "Ce lexème s'analyse, en synchronie protoromane, comme un dérivé en */ani/, suffixe (rare) à valeur collective" (cfr. DÉRom: s.v. */montania). Como se ve, el problema sigue en curso, pues seguimos con un étimo reconstruido, pero con un nuevo elemento compositivo que puede ayudar a comprender mejor la estructura de la voz en sí y que viene, además, a dar más luces respecto a la estructura, difusión y presencia del latín vulgar, de donde deriva, a posteriori este protorrománico del que se fundamenta en el DÉRom.

\section{4. ¿Hápax?}

Hay casos en que una voz ha sido definida una sola vez en un repertorio lexicográfico y no hay referencia alguna de esta. ¿Podemos en este caso hablar de voces fantasma (cfr. Álvarez de Miranda 2007)? ¿O lisa y llanamente podemos hablar de una sola recurrencia dentro de una codificación? ¿Puede ser ello un ejemplo de hápax? Por ejemplo, cuando se hace un estudio historiográfico de un diccionario, lo que se suele hacer es leerlo para determinar qué voces tiene y cuáles son sus aportes o cuáles son simples trasvases (es decir, el paso de voces) que este diccionario tiene con otros diccionarios. Muchas veces en este trabajo uno se lleva sorpresas como esta: la de no encontrar la voz en otro repertorio lexicográfico.

4.1 En el caso del habitante de Betsamés, un betsamita, hemos detectado que, dentro del corpus cotejado, la voz no ha aparecido lematizada hasta el día de hoy, salvo en el Diccionario de chilenismos y de otras voces y locuciones viciosas del sacerdote chileno Manuel Antonio Román:

BETSAMITA, adj. y ú.t.c.s. com. Habitante de Betsamés, ciudad levítica de la tribu de Judá en la frontera con la de Dan, célebre por haber estado en ella el arca de la alianza y por el castigo que se llevaron sus moradores. Falta esta voz en el Dicc., en el cual figuran otras de esta misma naturaleza, tanto o menos conocida que esta. (1901-1908)

4.2. De la misma familia léxica solo tenemos el caso del Diccionario enciclopédico hispano-americano (Montaner y Simón editores), que incluye el topónimo Betsames, mas no su gentilicio (cfr. Tomo III s.v. Betsames).

4.3. Fallido el cotejo con el resto de los diccionarios y en la búsqueda en los bancos de palabras oficiales, en búsquedas en la red, lo hemos encontrado en el diccionario de la biblioteca en línea de la Watch Tower Bible and Tract Society of Pennsylvania, ni más ni menos. Es decir, en el gigante editorial que los Testigos de Jehová divulgan por el mundo. Por lo tanto, fuera del Diccionario de Román, encontramos el gentilicio betsamitas en el siguiente texto de la biblioteca en línea del Watch Tower: "En 1 Samuel 6:18 la Versión Torres Amat (1953) hace referencia a "la Piedra Grande llamada después Abel”, y la nota al pie de la página lee: "Abel significa 'luto' o 'llanto': nombre que se cree dado a aquel lugar por causa de la gran mortandad de los betsamitas." (Biblioteca en línea Watchtower). 
4.4. Esto no se correlaciona, de todos modos, con la cantidad de veces que podemos encontrar el adjetivo, sea en relación con Josué, el betsamita, el que tiene mayor número de recurrencias o en relación a los pasajes bíblicos relacionados con los habitantes de Betsamés. Queda, de todos modos, hacer un estudio recabado de las biblias y ver cómo se expresa el gentilicio en ellas.

\section{Una voz desusada y su origen andaluz}

Hay casos en donde, dentro de la tradición lexicográfica académica, una voz suele marcarse como propia de una zona peninsular, aunque se haya detectado que la voz se usa o se haya usado en Hispanoamérica o de alguna zona de esta. Asimismo, no se suele hacer referencia, las más veces, si la voz en cuestión es histórica o no. Con este contexto, en la mayoría de los casos, la tradición lexicográfica académica sigue tratando algunas voces como provincialismos peninsulares las más veces. Sucede, sobre todo, con provincialismos de Asturias o de Andalucía, focos de traspaso léxico al nuevo mundo fundamentales, como se ha visto en la bibliografía relativa al léxico hispanoamericano. Muchas veces, por una cosa de no revisitar críticamente ciertos artículos lexicográficos, esta información no se menciona. Además, mutatis mutandis, la información diatópica que aparece en la tradición lexicográfica académica es la hispanoamericana, silenciando la provincial española. Es este, como se ve, todo un espacio crítico en el que trabajar e investigar, si de lexicología histórica estamos hablando.

5.1. Tomemos el caso de una voz histórica: hilo de acarreto, que se define como “Cordel delgado de cáñamo” y que el diccionario académico le da la marca diatópica de Andalucía (DLE).

5.2. Que la voz se usó en el resto de Hispanoamérica lo comprobamos con Rivodó (1889: 174), quien afirma que es "de uso corriente" en Venezuela. La voz, en efecto, es de larga data y extendida en Hispanoamérica. Aquí, para corroborarlo, más que CORDE o la Hemeroteca de la BNE, nos basamos en el Léxico Hispanoamericano, proyecto del hispanista norteamericano Peter Boyd-Bowman. No podemos dejar de mencionar este sitio abierto en la red, justamente, porque el proyecto es una instancia fundamental para todo aquel que quiera estudiar el español de América. En 1967, Peter Boyd-Bowman empezó a recoger datos para trabajar con el léxico hispanoamericano (proyecto llamado Léxico Hispanoamericano, LHA) y en 1971 publicó los materiales para estudiar el español de América del siglo XVI. Sin embargo, la cantidad de material que acopió era tal que la posibilidad de publicarlo en papel fue inviable. Es por esto que, en 1982, el Hispanic Seminary of Medieval Studies empezó a publicar el LHA en microfichas. Con los avances de la computación, en 1994, gracias al National Endowment for the Humanities, el LHA se transformó en una base de datos en CD-ROM. Por último, en 2015, gracias al Graduate School of the University of Wisconsin-Madison, se publicó la versión en línea del LHA, de la que se puede acceder libremente. Justamente, en el LHA hilo de acarreto se registra en 1512 para Puerto Rico, en 1544 para Puebla, en 1559 para Potosí, en 1683 para el Reino de Nueva Granada y el más nuevo, dentro del corpus, en 1780 para Río de la Plata.

5.3 En Chile es conocido y usado desde el tiempo de la colonia; y así leemos en la Histórica relación del P. Ovalle (l.I, c. IV): "Sacan también el hilo que llaman de acarreto, y otros géneros de cordeles que sirven para varios efectos" (2007 [1646]).

5.4. Dentro de la lexicografía general española, la mención más remota es la que nos entrega la misma Academia desde la edición de 1780 con la marca de Andalucía, algo que seguimos comprobando con Alcalá Venceslada (1980 [1933]) en su 
Vocabulario andaluz. Así nos lo cita, además, Alvar Ezquerra (2000) en su Tesoro de las hablas andaluzas, quien menciona, además, el Vocabulario de Alcalá Venceslada. También en Canarias, tal como lo ilustra el Diccionario Histórico del Español de Canarias (DHECan, proyecto dirigido por Corrales y Corbella), quien lo data en 1519 y cita, además, para América, el léxico de Peter Boyd Bowman.

5.5. La voz está registrada en CORDE desde 1575, con el zamorano Diego de Torres Bollo y su Relación del origen y suceso de los Xarifes, publicada en Sevilla. La voz solo tiene una segunda recurrencia en CORDE para España: en 1653, con el lopereño Bernabé Cobo y su Historia del Nuevo Mundo. Posteriormente, solo hace referencia a Perú (1685, Jacinto Hevia Bustos, Vejamen al doctor Antonio Correas) y a Filipinas (1754, Historia general de Filipinas). No hay referencias en CREA, por lo que pensamos que la voz, un andalucismo de origen, se extendió rápidamente a Canarias -en donde se mantieney a Hispanoamérica y Filipinas.

5.6. Debe haber sido una voz de uso frecuente en Hispanoamérica, puesto que la Hemeroteca digital parte entregando numerosos casos de México desde 1729. Lo interesante, en este caso, es que la voz ha dejado de usarse en España (no aparece en Moliner, tampoco en el DEA 1999 ni en CLAVE) y se mantiene en Canarias. Asimismo, el Diccionario usual de la academia sigue marcándolo como voz de Andalucía. Como sea, la confirmación de que la voz se asentó tempranamente en Hispanoamérica es gracias al LHA de Boyd-Bowman.

\section{6. ¿Poligénesis?}

Hay casos en que por más que se confirme la tesis monogenética del origen de una voz, en este caso, una voz propia de Hispanoamérica, los datos que nos pueda dar el cotejo, en la revisión filológica, para dar con entera certeza el origen de la voz en cuestión, puede traernos una que otra sorpresa.

6.1. Lo pensamos, sobre todo, por un caso, como lo es el chilenismo amasandería (voz que se define como 'sitio donde se hace pan'), así como amasandero ('Persona que amasa la harina para hacer pan y otros alimentos de masa'), voces tan características del español de Chile que suelen tratarse como chilenismos estrictos.

6.2. Sin embargo, gracias al cotejo con otras obras lexicográficas y afines, se ha demostrado que la voz, fuera de Chile, se usó también en Colombia, tal como podemos comprobar con la información que nos entrega Cuervo en sus Apuntaciones quien, en sus ediciones de 1867-1872, 1876 y 1885, la presenta dentro de la lista de voces que se derivan de raíces españolas “y no lo son ellas mismas". En efecto, en estas ediciones, Cuervo informa que en Bogotá se le llama amasandería a la "panadería, tahona", en palabras del autor colombiano. En las ediciones de 1907 y 1914, en el capítulo "Voces nuevas", Cuervo señala que de los nombres en - ero relacionados con oficio, se forman nombres en -ía, los cuales significan el oficio en abstracto o el local donde este se ejerce o donde se venden los artículos de su fabricación. En el caso de amasandería, explica, no existe el primitivo en -ero, mas sí el nombre relacionado con el lugar, usando el sufijo -ería y ejemplifica, además, con otros casos. Esta última información que presenta Cuervo no se da en el caso de Chile, puesto que se tiene al amasandero y es una voz de larga data, puesto que se lematiza en el primer diccionario de Chilenismos, el de Rodríguez (1875), quien define las amasanderías como las “panaderías pequeñas, generalmente dirigidas por mujeres". Uribe (1887), para Colombia, también incluye amasandería en su diccionario sin ningún tipo de normatividad. No así el chileno Ortú- 
zar (1893), quien la marca como una incorrección y, a diferencia de la información que entregó Rodríguez para la voz, este solo se limita a definirla como 'tahona' o 'atahona'.

6.3. En la tradición lexicográfica europea es Zerolo (1895) quien primero incluye la voz, dando dos acepciones: una para Colombia como "panadería, taberna" y otra para Chile como "La panadería pequeña o dirigida por mujeres", citando, como fuente, a Rodríguez (1875). Desde Europa, Toro y Gómez (1901), Alemany (1917) y Rodríguez-Navas (1918) siguen con la información entregada por Rodríguez.

6.4. La tradición académica manual desde 1927 hasta 1989 tiene la voz para Colombia y Chile y diastráticamente, como un vulgarismo. Lematizada por vez primera en el Diccionario usual de 2001, solo para Chile, remite a panadería, 'sitio, casa o lugar donde se vende pan'.

6.5. La tradición lexicográfica de diccionarios de americanismos, nos informa que la voz podría haberse usado en Venezuela, porque Malaret (1931) y Morínigo (1966), incluyen a Venezuela en su marcaje, junto con Chile y Colombia. Sin embargo, dudamos de dicha realización, puesto que no encontramos información alguna respecto a esta diatopía. Más aún si en el suplemento de 1942 de Malaret solo dejó las marcas para Colombia y Chile.

6.6. Como sea, que la voz solo se sigue usando en Chile lo corrobora, además, la última edición del diccionario de chilenismos de la Academia Chilena de la Lengua (DUECh 2010) y el único caso que hay en CREA para la voz es para Chile. Lo mismo el léxico de Boyd-Bowman para amasandero (1962). Contamos, sin embargo, con un a interesante anomalía: Orellana (1891 [1871]), desde Barcelona, describió: "Se trata del departamento destinado a amasar y cocer el pan en un hospital militar. Pues a eso se le llama en todas partes panadería y no amasandería. ¡Qué cosas tienen esos madrileños!" (s.v. amasandería). Dejamos esta pista para una pesquisa, creemos, necesaria y en donde tantos los registros en papel como en internet, sean hispánicos o internacionales nos quedaron cortos.

\section{Una voz histórica que no parece histórica}

Hay casos en donde, dentro de la tradición lexicográfica académica, una voz suele marcarse como propia de Hispanoamérica o de alguna zona de esta. Asimismo, no se suele hacer referencia, las más veces, si la voz en cuestión es histórica o no. Con este contexto, en la mayoría de los casos, la tradición lexicográfica académica sigue tratando algunas voces como de uso. A su vez, mutatis mutandis, la información diatópica que aparece en la tradición lexicográfica académica es la hispanoamericana, silenciando la provincial española. Es este, como se ve, todo un espacio crítico en el que trabajar e investigar, si de lexicología histórica estamos hablando.

7.1. Es lo que tenemos con belduque, que se define como 'cuchillo grande de hoja puntiaguda' (DLE). Román en su Diccionario de chilenismos y de otras voces y locuciones viciosas problematiza la voz de la siguiente forma:

Belduque, m. Cierto cuchillo de hoja puntiaguda y mango de madera y de una sola pieza, que estuvo aquí muy en uso treinta años atrás. Llamábase también cuchillo de belduque o cuchillo belduque, adjetivando esta última voz. Créela Cuervo venida de España y derivada de Balduque, que era como pronunciaban los españoles del siglo XVI el nombre de Bois-le-Duc, ciudad de Holanda, célebre en las guerras de los Países Bajos y en la cual hasta hoy florecen las fábricas de cuchillos. Tanto 
en Colombia como en Chile se ha dicho también balduque, lo que se acerca más a la casi cierta etimología. Entre otros usos, sirvió este cuchillo para matar y descuartizar reses: en este caso podría reemplazarse por el castizo jifero. (1901-1908)

7.2. Los primeros testimonios de esta voz se dan prácticamente en toda Hispanoamérica desde una etapa temprana. Una vez más el Léxico Hispanoamericano (LHA) nos ayudó para corroborar las primeras dataciones: 1549 para México (Protocolos de Puebla de los Ángeles, Boyd Bowman); 1559 para Bolivia (Historia de la villa imperial de Potosí, Arzáns de Orsúa y Vela, Boyd Bowman); 1581 para Guatemala (Archivo documental centroamericano, Boyd Bowman); 1626 para Chile (Historia del tribunal del Santo Oficio de la Inquisición en Chile, Medina, Boyd Bowman); 1638 para Colombia (Juan Rodríguez Freyle, CORDE), todas como cuchillo de belduque.

7.3. La voz, tal como informa Román, fue usual hasta el Chile decimonónico. Esto nos lo corrobora Gormaz (1860), quien enmienda un berduque por balduque. Cuervo, desde la primera edición de sus Apuntaciones, propone el étimo de la voz (1867-1872: §732) hasta confirmarlo en las ediciones posteriores. Asimismo, da cuenta de la extensión de la voz en Hispanoamérica: "desde México a Chile" (1907: \$656). Rodríguez (1875) para Chile, Uribe (1887) desde Colombia y Echeverría y Reyes (1900) para Chile son los únicos que rastreamos nosotros dentro de la tradición lexicográfica hispanoamericana. García Icazbalceta (1899) para México hace referencia a que la voz está en desuso, dentro de la norma culta y que "Hoy solo el pueblo usa esta voz".

7.4. La voz fue incorporada en el diccionario usual de 1925 con las marcas diatópicas de Colombia, Chile y México; justamente, porque la voz había aparecido en algunos de los repertorios lexicográficos de estos países. Sin embargo, en la mayoría de estos autores hemos constatado que la voz está en desuso o está restringida a determinados espacios. Por ejemplo, Yrarrázabal (1945) propone que belduque, en Chile, se elimine del diccionario usual por no tener uso en el país y Morales Pettorino (1984) lo marca como desusado. La mantención de las marcas diatópicas es irregular dentro de la tradición lexicográfica más actual. Por ejemplo, Malaret, en la tercera edición de su diccionario (1946), descarta Colombia y solo deja México y Chile.

7.5. La tradición académica usual descarta en la edición de 1956 la marca Chile; en la de 1992 la de México, la que retoma en la edición de 2001 hasta la fecha. El Diccionario de Americanismos (DA) da cuenta de la voz para México y Colombia, pero para ambos obsoleto.

7.6. Un último dato que queremos presentar y que invita a seguir investigando por el destino y usos de belduque es lo que encontramos en Fernández (1900), quien informa que, para Chile, se dio la transición semática "débil, enclenque, apocado" y da, para ello, la autoridad del escritor Daniel Barros Grez (autor costumbrista del XIX y uno de los fundadores del teatro chileno). Dicha transición no prosperó, porque no ha tenido vigencia alguna en los repertorios lexicográficos de chilenismos y no hemos dado con ella en nuestra búsqueda. Como se puede comprobar, una voz, en este caso histórica o desusada, requiere el constante trabajo filológico de cotejo, sobre todo para cerciorarnos de que esta voz tiene dicha tipología diacrónica. Por ahora, y dentro del tópico que nos convoca, solo nos queda insistir en la ayuda que puede dar un sitio en internet como lo es el Léxico Hispanoamericano (LHA), el que ha sido fundamental para poder trazar esta diacronía. 


\section{Un indigenismo vigente en Chile}

Otra instancia en que el Léxico hispanoamericano (LHA) ha sido de gran ayuda para determinar la diatopía de una voz es en la construcción al apa. En este caso queremos ejemplificar la función de dicho banco, justamente, el caudal léxico no hispánico que conforma y caracteriza, sobre todo, al español hablado en América. En este caso en particular son los indigenismos que han pasado a la lengua española.

8.1. En el caso de la voz apa, Lafone Quevedo, en su Tesoro de Catamarqueñismos (1927 [1898]), comenta que procede de $a p a$, que en quechua significa llevar y es la expresión que los niños dicen a sus nodrizas: apa, "llévame o cárgame". En Chile, complementa Román (1901-1908), se usa como a cuestas, entre toda clase de personas como la locución adverbial al apa.

8.2. Lo que nos interesa de al apa es la extensión de uso del quechuismo, puesto que sigue teniendo absoluta vigencia en Chile. En la Argentina, fuera de lo que propone Lafone Quevedo, la voz no tiene registro alguno. En Chile, dentro de la tradición lexicográfica de diccionarios de chilenismos, se lematiza por primera vez en Rodríguez (1875), le siguen Ortúzar (1893), Echeverría y Reyes (1900), Román (1901-1908) y Medina (1928). Lenz, en su Diccionario etimológico de las voces chilenas derivadas de las lenguas indígenas americanas (1979 [1904-1910]) afirmará que la voz se usa frecuentemente en Santiago.

8.3. En la tradición lexicográfica europea, la locución fue incorporada por primera vez en Alemany (1917) para Chile y le siguió el usual en 1970. No tenemos datos ni certeza de por qué el Diccionario Histórico de la Academia (1996) agregó, junto a Chile, el uso en Ecuador.

8.4. Las referencias al apa que podemos encontrar en el Léxico hispanoamericano (LHA) y CREA son, con este valor, para Chile o haciendo referencia a Chile.

\section{Resultados}

Con esta pequeña muestra lo que quisimos fue presentar, dentro de diversos aspectos, niveles y pertinencia dentro de la argumentación del problema en sí; es decir, cuán relevante es el uso y recurso del banco de palabras o el diccionario en línea. Nos detuvimos, por ejemplo, en el caso de una voz presente en la fraseología: sentada esta/la baza, gracias a la observación crítica de un diccionario de principios del siglo veinte. Esta observación, dicho sea de paso, no había sido tenida en cuenta en el universo lexicográfico hispánico. En efecto, gracias a esta observación y su posterior desglose y análisis, detectamos un interesante caso de interferencia asociativa fonética, la que solo podía corroborarse con la identificación del étimo de la voz en cuestión. En este caso, el uso de corpus lexicográficos en línea de otros idiomas, como el italiano medieval y el occitano y el francés fueron fundamentales para poder comprobar la hipótesis.

Por otro lado, por la revisión constante de los étimos que nos proveen tanto Corominas como el DLE, quisimos corroborar hasta qué punto la voz montaña sigue teniendo un étimo hipotético. Para ello recurrimos al DÉRom, el proyecto diccionarístico etimológico de las lenguas románicas más actualizado y está en línea. Si bien el étimo sigue siendo hipotético 
mas, gracias a los avances en el estudio del protorrománico, se ha reformulado el étimo y se ha destacado, gracias a ello, un elemento morfológico novedoso.

A su vez, puede que el cotejo de una voz nos lleve por otros espacios en la red, que no tengan que ver con proyectos universitarios para bases de datos o diccionarios en línea, como nos sucedió con la biblioteca digital del Watch Tower Bible and Tract Society of Pennsylvania, del gigante editorial de los Testigos de Jehová.

En otros casos, hicimos uso del banco de palabras dirigido por el hispanista norteamericano Peter Boyd-Bowman: el Léxico Hispanoamericano (LHA), en línea y de libre acceso. Esta obra, la más importante para poder trabajar y cotejar con el español hablado en América, nos ayudó a determinar si una voz histórica se usó y desde cuándo se usó, así como su difusión en el continente, como en el caso de belduque o hilo de acarreto. A su vez, gracias al LHA pudimos comprobar que voces como amasandería o al apa se siguen usando solo en Chile hasta la actualidad.

\section{Conclusiones}

Tal como comentábamos en la introducción, una investigación acerca del léxico, sobre todo desde una perspectiva histórica y dialectológica, requerirá siempre la búsqueda de datos y cotejo de información. Esto se comprueba en este mismo ensayo, en donde las referencias bibliográficas dan, de por sí, para una reflexión crítica independiente, creemos. En efecto, los diccionarios, así como la información que se encuentra en internet, serán fuentes fundamentales para hacer lexicología histórica. También anunciamos que la información que nos entrega la bibliografía, digamos oficial o clásica de la hispanística será fundamental, pero insuficiente. Por lo mismo, bancos de palabras académicos como CORDE o CREA, o la Hemeroteca digital, de la BNE serán instancias determinantes, pero no las únicas. Por lo mismo es fundamental que todo quien desee investigar acerca del léxico hispánico deba abrirse a otras tradiciones lingüísticas o a otros espacios que no sean única y exclusivamente los hispánicos. En efecto, estos sitios en la red pueden ayudar a complementar o comprobar lo que se está investigando. En síntesis, lo que quisimos dar cuenta en este ensayo fue, justamente, dar cuenta de la relevancia de los medios digitales internacionales como corpus de investigación para hacer historia del léxico español. Insistimos en ello: el ecosistema digital global es un espacio lingüístico fundamental, que provee de datos algunas veces no tratados en la literatura académica u oficial de la hispanística, como diccionarios en línea del italiano medieval, del occitano o diccionarios etimológicos del francés o de las lenguas románicas.

En otros casos, lo que encontramos fue la existencia de corpus y bancos de palabras especialmente elaborados para la tradición hispánica, pero estos no están dentro de los bancos académicos u oficiales, de los que solemos echar mano las más veces. Muchas veces son proyectos de universidades anglosajonas (como el LHA) y si no estamos al día en lo que se está investigando en relación a la hispanística, podemos quedar fuera de todas estas herramientas que están en la red al acceso de cualquiera.

Otras veces, como vimos en un caso, más que proyectos universitarios, de filólogos y lingüistas, lo que nos ayudó fue el trabajo con bibliotecas en línea de proyectos que de buenas a primeras nos pueden, incluso, sorprender, como nos sucedió con el Watch Tower Bible and Tract Society of Pennsylvania. 
En este ensayo, en síntesis, lo que quisimos presentar fueron algunos casos en donde la investigación en lexicología histórica se complementó con los datos que aportó, justamente, el ecosistema digital total. Gracias a una metodología de trabajo filológica, que implicó la revisión y el cotejo de diversas fuentes bibliográficas, partiendo por diccionarios, seguido por el uso de los bancos de palabras oficiales (RAE o la Hemeroteca digital), sea de la tradición hispánica o de la lingüística románica, entre otros espacios fue fundamental en los casos en donde no hubo ningún tipo de información concluyente o definitoria. Por lo tanto, como investigadores del léxico y su historia, quedamos en deuda con las páginas que universidades internacionales, así como proyectos y centros de investigación han financiado para que los resultados estén en el aire, a mano del investigador o curioso y de libre acceso.

\section{Referencias bibliográficas}

Academia Chilena de la Lengua. 2010. DUECh. Diccionario de uso del español de Chile. Santiago: MN.

Alcalá Venceslada, Antonio. 1980 [1933]. Vocabulario andaluz. Madrid: Gredos.

Alemany, José. 1917. Diccionario de la lengua española. Barcelona: Ramón Sopena.

Alonso, Amado. 1947. "Trueques de sibilantes en el antiguo español”. Nueva Revista de Filología Hispánica. Año 1, nº1, pp. 1-12.

Alvar Ezquerra, Manuel. 2000. Tesoro léxico de las hablas andaluzas. Madrid: Arco Libros.

Álvarez de Miranda, Pedro. 2007. “Palabras y acepciones fantasma en los diccionarios de la Academia”. Alicante: Biblioteca Virtual Miguel de Cervantes.

Asociación de Academias de la Lengua Española (ASALE). 2010. DA. Diccionario de americanismos. Madrid: Santillana.

Barcia, Roque. 1880. Primer diccionario general etimológico de la lengua española. Madrid: Establecimiento tipográfico de Álvarez Hermanos. Tomo primero.

Beltrami, Pietro (dir.). 1998-. Tesoro della lingua italiana delle origini (TLIO). Florence, CNR/Accademia della Crusca. http://tlio.ovi.cnr.it/TLIO/.

Boyd-Bowman, Peter. 2003. Léxico hispanoamericano. 1493-1993. Editado por Ray Harris-Northall y John J. Nitti, edición en CD-ROM. Nueva York: Hispanic Seminary of Medieval Studies.

Calandrelli, Mathias. 1916. Diccionario Filológico-Comparado de la lengua Castellana. Buenos Aires: Imprenta de G. Kraft. Tomo duodécimo.

Calandrelli, Mathias. 1881. Diccionario Filológico-Comparado de la lengua Castellana. Buenos Aires: Imprenta de Biedma. Tomo tercero

Corominas, Joan y Pascual, José Antonio. 1981. Diccionario crítico etimológico castellano e hispánico. DCECH. Madrid: Gredos. Vol. IV

Corominas, Joan y Pascual, José Antonio. 1980. Diccionario crítico etimológico castellano e hispánico. DCECH. Madrid: Gredos. Vol. I 
Corrales, Cristóbal y Corbella, Dolores. 2013. Diccionario Histórico del Español de Canarias (DHECan). Tenerife: Instituto de Estudios Canarios.

Covarrubias, Sebastián de. 2006 [1611]. Tesoro de la lengua castellana o española. Madrid: Iberoamericana.

Cuervo, Rufino José. 1914. Apuntaciones críticas sobre el lenguaje bogotano. París: Macon, Protat frères, imprimeurs. 6 a edición

Cuervo, Rufino José. 1907. Apuntaciones críticas sobre el lenguaje bogotano. París: A. \&R. Roger y F. Chernoviz, editores. 5 a edición.

Cuervo, Rufino José. 1885. Apuntaciones críticas sobre el lenguaje bogotano. Chartres: Imprenta de Durand.

Cuervo, Rufino José. 1876. Apuntaciones críticas sobre el lenguaje bogotano. Bogotá: Imprenta de Echeverría hermanos.

Cuervo, Rufino José. 1867-1872. Apuntaciones críticas sobre el lenguaje bogotano. Bogotá: Arnulfo M. Guarín.

DÉRom=Buchi, Éva \& Schweickard, Wolfgang (dir.).2008-. Dictionnaire Étymologique Roman (DÉRom). Nancy: ATILF. http://www.atilf.fr/DERom

Domínguez, Ramón Joaquín. 1869. Nuevo suplemento al Diccionario Nacional o gran Diccionario Clásico de la lengua española. Madrid: Imprenta y Librería Universal de los Sres. Crespo, Martín y Comp. Editores.

Echegaray, Eduardo de. 1887. Diccionario general etimológico de la lengua española. Madrid: Álvarez Hermanos, Impresores. Tomo primero.

Echeverría y Reyes, Aníbal. 1900. Voces usadas en Chile. Santiago: Imprenta Elzeviriana.

Fernández, Abraham. 1900. Nuevos chilenismos o Catálogo de las voces no registradas en los diccionarios de Rodríguez y Ortúzar. Valparaíso: Talleres de San Vicente de Paul.

Franciosini, Lorenzo. 1620. Vocabolario español-italiano, ahora nuevamente sacado a luz. Roma: Juan Pablo Profilio.

García Icazbalceta, Joaquín. 1899. Vocabulario de mexicanismos comprobado con ejemplos y comparado con los de otros países hispano-americanos. Obra póstuma publicada por su hijo Luis García Pimentel. México: Tipografía y litografía "La europea".

Gormaz, Valentín. 1860. Correcciones lexigráficas. Valparaíso: Imprenta del Comercio.

Kany, Charles. 1962. Semántica hispanoamericana. Madrid: Aguilar.

Lafone Quevedo, Samuel. 1927 [1898]. Tesoro de catamarqueñismos. Nombres de lugares y apellidos indios con etimologías y eslabones aislados de la lengua cacana. Buenos Aires: Imprenta y casa editora Coni.

Lenz, Rodolfo. 1979 [1904-1910]. Diccionario etimológico de las voces chilenas derivadas de las lenguas indígenas americanas. Edición dirigida por Mario Ferreccio. Santiago: Universidad de Chile, Seminario de Filología Hispánica.

Malaret, Augusto. 1946. Diccionario de americanismos. Buenos Aires: Emecé editores. Tercera edición.

Malaret, Augusto. 1942. Diccionario de americanismos: suplemento. Buenos Aires: Academia Argentina de Letras. Tomo primero, letras A-E. 2 a edición. 
Malaret, Augusto. 1931. Diccionario de americanismos. San Juan: Imprenta Venezuela $1^{\text {a }}$ edición. Maldonado, Concepción (dra.). 1996. CLAVE. Diccionario de uso del español actual. Madrid: SM.

Medina, José Toribio. 1928. Chilenismos. Apuntes lexicográficos. Santiago de Chile: Imprenta universo/Sociedad Imprenta/ Literaria Universo.

Meyer-Lübke, Wilhelm. 1935 [1911-1920]. REW. Romanisches Etymologisches Wörterbuch. Heidelberg: Winter.

Mez de Braidenbach, Nicolás. 1670. Diccionario muy copioso de la lengua española y alemana hasta agora nunca visto, sacado de diferentes autores. Viena: Juan Diego Kürner.

Minsheu, John. 1617. Vocabularium hispanicolatinum et anglicum copiossisimum. Londres: Joanum Browne.

Moliner, María. 1966-1967. DUE. Diccionario de uso del español. Madrid: Gredos.

Montaner y Simón editores. 1887-1910. Diccionario enciclopédico Hispano-Americano. Barcelona: Montaner y Simón, editores.

Morales Pettorino, Félix (director). 1984. DECh Diccionario ejemplificado de chilenismos y de otros usos diferenciales del español de Chile. Santiago: Editorial Universitaria. Tomo I.

Orellana, Francisco. 1891 [1871]. Cizaña del lenguaje. Vocabulario de disparates, extranjerismos, barbarismos y demás corruptelas, pedanterías y desatinos introducidos en la lengua castellana. Barcelona: Librería de Antonio J. Bastinos.

Ortúzar, Camilo. 1893. Diccionario manual de locuciones viciosas y de correcciones del lenguaje. Con indicación de algunas palabras y ciertas nociones gramaticales. San Benigno Canavese: Imprenta salesiana.

Oudin, César. 1607. Tesoro de las dos lenguas francesa y española. Thresor de deux langues françoise et espagnolle. Paris: Marc Orry.

Ovalle, Alonso de. 2007 [1646]. Histórica Relación del Reyno de Chile. Cervantes Virtual.

Palet, Juan. 1604. Diccionario muy copioso de la lengua española y francesa. París: Matthieu Gillemot.

Real Academia Española. 2014. Diccionario de la lengua española (DLE). Madrid: Espasa.

Real Academia Española. 2001. Diccionario de la lengua española. Madrid: Espasa.

Real Academia Española. 1996. Diccionario histórico de la lengua española. Madrid: Imprenta Aguirre. Tomo III, Fascículo 22 y 23.

Real Academia Española. 1992. Diccionario de la lengua española. Madrid: Espasa Calpe.

Real Academia Española. 1990 [1726]. Diccionario de Autoridades. Madrid: Gredos. Letras A y B.

Real Academia Española.1970. Suplemento al Diccionario de la lengua española. Madrid: Espasa-Calpe.

Real Academia Española. 1956. Diccionario de la lengua española. Madrid: Espasa-Calpe.

Real Academia Española. 1899. Diccionario de la lengua castellana por la Real Academia Española. Madrid: Imprenta de los señores Hernando y compañía. 
Rivodó, Baldomero. 1889. Voces nuevas en la lengua castellana. París: Librería española de Garnier y hermanos. Rodríguez, Zorobabel. 1875. Diccionario de chilenismos. Santiago: Imprenta del Intendente.

Rodríguez-Navas y Carrasco, Manuel. 1918. Diccionario general y técnico Hispanoamericano. Madrid: Cultura Hispanoamericana.

Román, Manuel Antonio. 1901-1908. Diccionario de chilenismos y de otras voces y locuciones viciosas. Tomo I: A, B, C y suplemento á estas tres letras. Santiago: Imprenta de la Revista católica.

Rosal, Francisco del. 1992 [1611]. Diccionario etimológico. Madrid: Consejo Superior de investigaciones Científicas.

Seco, Manuel, Andrés, Olimpia y Ramos, Gabino. 1999. DEA. Diccionario del español actual. Madrid: Aguilar.

Selig, María (dra.). 2012-. Dictionnaire de l'occitan médiéval (DOM). Institut de Philologie romane del' Université de Munich (LMU). http://dom-en-ligne.de.

Sobrino, Francisco. 1705. Diccionario nuevo de las lenguas española y francesa. Bruselas: Francisco Froppens.

Stevens, John. 1706. A new spanish and english dictionary. Londres: George Sawbridge.

Toro y Gómez, Miguel de. 1901. Nuevo diccionario enciclopédico ilustrado de la lengua castellana. París/Madrid: Librería Armand Colin.

Uribe, Rafael. 1887. Diccionario abreviado de galicismos, provincialismos y correcciones de lenguaje con trescientas notas explicativas. Medellín: Imprenta del Departamento.

Valdés, Juan de. 1969 [1535]. Diálogo de la lengua. Edición de Juan M. Lope Blanch. Madrid: Clásicos Castalia.

Vittori, Girolamo. 1609. Tesoro de las tres lenguas francesa, italiana y española. Thresor des trois langues françoise, italliene et espagnolle. Ginebra: Philippe Albert \& Alexandre Pernet.

Wartburg, Walther Von. 1910-1940. Französisches Etymologisches Wörterbuch (FEW). Analyse et Traitement Informatique de la Langue Française (ATILF) y Université de Lorraine. http://atilf.fr/lecteur FEW.

Watch Tower Bible and Tract Society of Pennsylvania. 2018. Biblioteca en línea Whatchtower. [https://wol.jw.org/es/ $\mathrm{wol} / \mathrm{h} / \mathrm{r} 4 / \mathrm{lp}-\mathrm{s}]$

Yrarrázabal, José Miguel. 1945. Chilenismos. Santiago de Chile: Imprenta Cultura.

Zerolo, Elías. 1895. Diccionario enciclopédico de la lengua castellana. París: Garnier hermanos. 
